\title{
A interseccionalidade dos estudos da EJA, Educação Inclusiva e Formação Docente: um estado do conhecimento
}

\author{
The intersectionality of YAE, Inclusive Education and Teacher Education \\ studies: a state of knowledge
}

\section{La interseccionalidad de EJA, los estudios de la Educación Inclusiva y de Educación del Profesorado: un estado del conocimiento}

Rayssa Maria Anselmo de Brito

Professora doutoranda da Universidade Federal da Paraíba, João Pessoa, PB, Brasil

E-mail: rayssamtbrito@gmail.com ORCID: https://orcid.org/0000-0001-9389-6421

\section{Eduardo Jorge Lopes da Silva}

Professor doutor da Universidade Federal da Paraíba, João Pessoa, PB, Brasil

E-mail: eduardojorgels@gmail.com ORCID: https://orcid.org/0000-0002-5402-8880

Recebido em 17 de dezembro de 2020

Aprovado em 14 de abril de 2021

Publicado em 27 de maio de 2021

\section{RESUMO}

Presentes na Educação de Jovens e Adultos - EJA, as pessoas com deficiências conferem a esta modalidade da educação novas demandas formativas e práticas, por esta razão, o presente estudo visa analisar as pesquisas realizadas no campo da intersecção da EJA, Formação Docente e Educação Inclusiva, no período de 2017 a 2019. Para tanto, é realizada uma pesquisa bibliográfica do tipo estado do conhecimento e, por meio desta, uma análise de conteúdo, a qual revela quais categorias são mais recorrentes nas pesquisas analisadas. Logo, são ressaltados 04 (quatro) trabalhos, sendo 03 (três) dissertações e 01 (uma) tese, as quais partindo de seus contextos locais, apontam para a necessidade de investir-se esforços em compreender e potencializar os processos inclusivos de jovens e adultos com deficiências na EJA por meio da formação docente, sendo a realização de estudos acadêmicos um caminho possível para apresentar novos horizontes e as pesquisas de caráter interventivo e colaborativo, as principais opções teóricos-metodológicas presentes nos trabalhos analisados.

Palavras-chave: Educação Inclusiva; Educação de Jovens e Adultos; Formação Docente; Estado do Conhecimento.

\section{ABSTRACT}

Present in Youth and Adult Education - YAE, people with disabilities give this type of education new training and practical demands. For this reason, this study aims to analyze the research carried out in the field of the intersection of the YAE, Teacher Training and Inclusive Education, in the period from 2017 to 2019. For that, a bibliographic research of the state of knowledge type is carried out and, through this, a content analysis, which reveals which categories are more frequent in the researches analyzed. Therefore, 04 (four) works 
are highlighted, being 03 (three) dissertations and 01 (one) thesis, which starting from their local contexts, point to the need to invest efforts in understanding and enhancing the inclusive processes of young people and adults with disabilities in YAE through teacher training, with academic studies being a possible way to present new horizons and interventional and collaborative research, the main theoretical and methodological options present in the analyzed works.

Keywords: Inclusive Education; Youth and Adult Education; Teacher Education; State of Knowledge.

\section{RESUMEN}

Presentes en la Educación de Jóvenes y Adultos - EJA, las personas con discapacidad conferen a este tipo de educación de nuevas formaciones y demandas prácticas, por lo que este estudio tiene como objetivo analizar las investigaciones realizadas en el campo de la intersección de EJA, Formación del Profesorado y Educación Inclusive, en el período de 2017 a 2019. Para ello, se realiza una búsqueda bibliográfica, del tipo de estado del conocimiento y, a través de ésta, un análisis de contenido, que revela qué categorías son más frecuentes en las investigaciones analizadas. Luego, se destacan 04 (cuatro) trabajos, siendo 03 (tres) disertaciones y 01 (una) tesis, que partiendo de sus contextos locales, señalan la necesidad de invertir esfuerzos en la comprensión y potenciación de los procesos inclusivos de los jóvenes y adultos con discapacidad en EJA a través de la formación del profesorado, siendo los estudios académicos una posible vía para presentar nuevos horizontes y la investigación intervencionista y colaborativa, las principales opciones teóricas y metodológicas presentes en los trabajos analizados.

Palabras llave: Educación Inclusiva; Educación de Jóvenes y Adultos; Formación del Profesorado; Estado del Conocimiento.

\section{Considerações iniciais}

Modalidades distintas da Educação de acordo com a Lei de Diretrizes e Bases da Educação Nacional no 9394/1996 (BRASIL, 2016), a Educação de Jovens e Adultos, assim como a Educação Especial, sempre se constituíram a partir de um lugar de lutas por visibilidade e de maior notoriedade tanto no âmbito das políticas públicas a exemplo de Machado (2009) e Carvalho (2014), como no tocante às pesquisas acadêmicas de Haas (2015); Siems (2012), entre outros. Deste modo, é com o intuito de analisar esse cenário acadêmico, que o presente estudo busca realizar um estado do conhecimento quando interseccionalizamos estas modalidades, todavia, recortando nesta, as contribuições e avanços situados também no campo da formação docente inicial/continuada. 
http://dx.doi.org/10.5902/1984686X63606

Para embasar nossa compreensão do que vem a ser o Estado do Conhecimento (EC), partimos da compreensão das autoras Morosini e Fernandes (2014, p. 155) as quais apresentam este exercício enquanto:

[...] uma matéria formativa e instrumental que favorece tanto a leitura de realidade do que está sendo discutido na comunidade acadêmica, quanto em relação a aprendizagens da escrita e da formalização metodológica para desenvolvimento do percurso investigativo.

O EC é definido como sendo a:

[...] identificação, registro, categorização que levem à reflexão e síntese sobre a produção científica de uma determinada área, em um determinado espaço de tempo, congregando periódicos, teses, dissertações e livros sobre uma temática específica (MOROSINI; FERNANDES, 2014, p. 155).

Para realização do EC do presente objeto (a formação docente na perspectiva da Educação Inclusiva no contexto da Educação de Jovens e Adultos), realizamos consultas em alguns portais de alcances nacionais, entre eles o Portal de Periódicos CAPES/MEC, o Banco de Teses e Dissertações presentes no Portal da CAPES, e, por fim, as produções realizadas no contexto local do Programa de Pós-Graduação em Educação da UFPB nos últimos cinco anos. Em todos esses, buscamos estudos, dissertações, teses, bem como artigos que de alguma forma tangenciavam o objeto aqui em tela.

No entanto, cabe ressaltar que encontramos em nossas buscas três estudos que já realizaram este mapeamento, até o ano de 2016, de sorte que uma vez tendo como ponto de partida os achados de Siems (2012), Haas (2015) e Silva e Campos (2018) ${ }^{1}$, os quais nos apresentam a escassez de estudos voltados na área, passamos em nossa pesquisa a afunilar nossas buscas para o interstício de 2017 a 2019, de modo a avançar nesse quadro analítico a fim de compreender quais são os conhecimentos já alcançados quando situamos o processo inclusivo de jovens e adultos com deficiências e a formação continuada dos docentes desta modalidade.

\section{Aspectos metodológicos da pesquisa}

Para a construção e norteamento das buscas realizadas nos portais supracitados, direcionamos a procura a partir dos descritores EJA/Educação de Jovens e Adultos; Inclusão/Educação Inclusiva e Formação Docente/Formação Continuada, combinando-os por meio de operadores booleanos "and" e "or" que nos permitiram combinar dois dos descritores citados, refinando as buscas de acordo com os títulos e observando os 
http://dx.doi.org/10.5902/1984686X63606

resumos dos trabalhos, todavia, ressaltando os que de fato se aproximaram de nosso objeto de pesquisa, os quais foram organizados em quadros. No Quadro 1, apresentamos o EC consultado no Portal de Periódicos do CAPES/MEC.

Quadro 1 - Estado do Conhecimento segundo o Portal de Periódicos CAPES/MEC (2017-2019)

\begin{tabular}{|c|c|c|c|c|}
\hline ANO & AUTOR(ES) & TíTULO & PERIÓDICO & SUPORTE \\
\hline 2018 & $\begin{array}{c}\text { SILVA, Maria do } \\
\text { Carmo Lobato da; } \\
\text { CAMPOS, Juliane } \\
\text { Aparecida de Paula } \\
\text { Perez. }\end{array}$ & $\begin{array}{l}\text { Formação de professores para } \\
\text { inclusão escolar na modalidade } \\
\text { de Educação de Jovens e } \\
\text { Adultos: análises das } \\
\text { pesquisas }\end{array}$ & $\begin{array}{l}\text { Política e } \\
\text { Gestão } \\
\text { Educacional }\end{array}$ & Artigo \\
\hline
\end{tabular}

Fonte: Portal de Periódicos CAPES/MEC (2020).

Sendo o único trabalho encontrado na intersecção das categorias EJA, Formação Docente e Educação Inclusiva, o trabalho de Silva e Campos (2018) realiza uma análise de conteúdo de 9 produções (dissertações e teses) defendidas entre 2008 e 2016, de modo que as autoras se utilizam da Biblioteca Digital de Teses e Dissertações Brasileiras (BDTD) e do Banco de Dissertações e Teses da Capes.

Nessa perspectiva, as autoras afirmam que:

A modalidade de EJA no ensino regular é um espaço privilegiado, com potencial para atender as necessidades específicas desta faixa etária e um ambiente ideal para prover a continuidade da aprendizagem escolar e desenvolvimento humano de todos aqueles que, por qualquer motivo, tenham sido excluídos da escola, inclusive jovens e adultos com deficiência (SILVA; CAMPOS, 2018, p. 1156).

Todavia, embora seja a EJA este espaço privilegiado, conforme destacam as autoras, faz-se necessário perceber também as precárias políticas públicas no âmbito da educação inclusiva, o que confere ao professor o papel de:

[...] espectador do processo educacional de jovens e adultos com deficiência inseridos na modalidade da EJA, a medida que o professor não tem uma compreensão clara sobre o processo de aprendizagem e desenvolvimento das pessoas com deficiência (SILVA; CAMPOS, 2018, p. 1165).

Em seguida, aprofundando nossa busca nos Portais de Teses e Dissertações Capes/MEC e Banco Digital (BDTD), encontramos no recorte temporal já assinalado, apenas 04 trabalhos, dos quais 03 (três) são dissertações e apenas 01 (uma) tese de doutoramento. 
http://dx.doi.org/10.5902/1984686X63606

Quadro 2 - Estado do Conhecimento - Portais de Teses e Dissertações (2017-2019)

\begin{tabular}{|c|c|c|c|c|}
\hline ANO & AUTOR & TíTULO & PROGRAMA & $\begin{array}{l}\text { TIPO DE } \\
\text { ESTUDO }\end{array}$ \\
\hline 2018 & $\begin{array}{l}\text { ARAUJO, Maria } \\
\text { Auxiliadora } \\
\text { Freitas Pimenta } \\
\text { de. }\end{array}$ & $\begin{array}{l}\text { Percepções Docentes sobre a } \\
\text { Inclusão de Estudantes com } \\
\text { Deficiência na Educação de } \\
\text { Jovens e Adultos: (im) } \\
\text { possibilidades no âmbito da } \\
\text { formação continuada' }\end{array}$ & $\begin{array}{l}\text { MPEJA - } \\
\text { UNEB }\end{array}$ & Dissertação \\
\hline 2018 & $\begin{array}{c}\text { BUENO, Melina } \\
\text { Brandt. }\end{array}$ & $\begin{array}{l}\text { Educação de Jovens e Adultos: } \\
\text { Formação Continuada } \\
\text { Colaborativa entre Professores da } \\
\text { sala comum e da Educação } \\
\text { Especial }\end{array}$ & $\begin{array}{l}\text { PPGEES- } \\
\text { UFSCAR }\end{array}$ & Dissertação \\
\hline 2019 & $\begin{array}{c}\text { ENVIY, Perla } \\
\text { Cristiane. }\end{array}$ & $\begin{array}{c}\text { Reflexões no processo } \\
\text { ensino/aprendizagem e suas } \\
\text { implicações na Formação Inicial } \\
\text { Docente: Contextos Inclusivos na } \\
\text { Educação de Jovens e Adultos }\end{array}$ & $\begin{array}{c}\text { PPGE - } \\
\text { UNICENTRO }\end{array}$ & Dissertação \\
\hline 2019 & $\begin{array}{l}\text { TASSINARI, Ana } \\
\text { Maria. }\end{array}$ & $\begin{array}{c}\text { Formação e prática pedagógica } \\
\text { de professores da EJA junto a } \\
\text { estudantes com deficiência } \\
\text { intelectual }\end{array}$ & $\begin{array}{l}\text { PPGEES - } \\
\text { UFSCAR }\end{array}$ & Tese \\
\hline
\end{tabular}

Fontes: Catálogo de Teses e Dissertações CAPES (2020); Banco Digital de Teses e Dissertações (2020).

Conforme evidenciado nos quadros acima, observamos poucos estudos voltados para esta temática, uma vez que em um universo tão representativo, apenas 4 pesquisas foram encontradas, destacamos Siems (2012, p. 63) ao afirmar que "ainda é fenômeno pouco estudado pelos pesquisadores da educação, tanto a partir do olhar da Educação Especial, quanto pelos educadores e pesquisadores vinculados à Educação de Jovens e Adultos", o que é reafirmado por Silva e Campos (2018, p. 1165):

[...] os estudos que envolvem processos de formação de professores para interface entre EJA e Educação Especial ainda são escassos, portanto, há necessidade de ampliar investigações com este foco, bem como ampliar o debate sobre (re)estruturação de currículos de cursos de licenciaturas e reconfiguração de programas para a formação continuada para atender a modalidade da EJA.

Logo, propomos na seção a seguir uma análise categorial em que aprofundaremos nosso olhar para os textos apresentados nos estudos analisados, de modo a compreender os caminhos percorridos e resultados encontrados pelas respectivas pesquisadoras. 
http://dx.doi.org/10.5902/1984686X63606

\section{Análise Categorial das pesquisas que interseccionam as áreas da EJA, Educação Inclusiva e Formação Docente}

Para construção da respectiva análise, nos ancoramos na análise de conteúdo elucidada por Bardin (2011), tendo como categorias a serem trabalhadas o lugar dos discursos identificados nas produções mapeadas (suas identificações e localidades de desenvolvimento das pesquisas); os tipos de pesquisas (aspectos metodológicos); os discursos sobre a EJA e a Educação Inclusiva; a Formação Docente e suas caracterizações; bem como as inferências ou os achados finais apresentados em seus relatórios finais.

\section{Os discursos presentes nas produções mapeadas: suas identificações e localidades de desenvolvimento das pesquisas}

Tomando como ponto de partida os processos de identificação das autoras das pesquisadoras, ressaltamos a predominância das vozes femininas nos trabalhos encontrados, bem como a trajetória destas no campo da Educação Especial, seja condição de Coordenadora Pedagógica em uma escola que oferece, com exclusividade, a Educação de Jovens e Adultos (ARAUJO, 2018), Professora da EJA (BUENO, 2018), Professora da Sala de Recursos que atendia alunos da EJA (TASSINARI, 2019), bem como Docente do Curso de Pedagogia (ENVIY, 2019).

Partimos dessa demarcação por compreender que tais identificações influem nas percepções e nas construções das pesquisas a serem analisadas, uma vez que a formação das mesmas, bem como as experiências construídas em suas atividades profissionais evidenciam ser estas pesquisadoras que desenvolvem seus trabalhos com muito embasamento e propriedade das realidades vivenciadas no cotidiano escolar.

Ressaltamos, também, no tocante à localidade em que as pesquisas se situam, sendo duas realizadas no estado de São Paulo, na Universidade Federal de São Carlos (UFSCAR), instituição a qual se distingue por possuir Programa de Pós-Graduação em Educação Especial, uma em Santa Catarina na Universidade Estadual do Centro Oeste (UNICENTRO) e uma em Salvador, na Universidade do Estado da Bahia (UNEB).

Deste modo, se voltarmos nosso olhar para o Quadro 02, observaremos que embora a região Nordeste do Brasil concentre o maior quantitativo de pessoas com deficiências (PcD), de acordo com o Censo do IBGE (2010), totalizando 26,63\% das PcD no país, bem 
http://dx.doi.org/10.5902/1984686X63606

como um alto percentual de jovens e adultos analfabetos ${ }^{2}$ (com taxas variando entre 11,9 a $16,3 \%$ ), aspecto este que contrasta frente ao percentual nacional de $6,8 \%$, observamos que entre as pesquisas encontradas no Quadro 2, são poucos os trabalhos desenvolvidos nesta região, o que nos remete ao fato de que:

[...] faz-se necessário considerar que a construção de uma produção cientifica está relacionada não só à pessoa/pesquisador que a produz, mas as influências da instituição na qual está inserida, do país em que vive e de suas relações com a perspectiva global (MOROSINI; FERNANDES, 2014, p. 156).

Como exemplo, temos o protagonismo do Programa de Pós-Graduação em Educação Especial da UFSCAR, o qual totaliza $50 \%$ das pesquisas de mestrado e doutorado elencadas no Quadro 02.

Para ratificar esta informação, buscamos no Programa de Pós-Graduação em Educação da UFPB os trabalhos (de mestrado e doutorado) cuja temática viesse a se aproximar de nossa busca. Observemos os achados sistematizados na Tabela 1.

Tabela 1 - Demonstrativo de teses e Dissertações do PPGE-UFPB

\begin{tabular}{|c|c|c|c|c|}
\hline \multirow{2}{*}{ DESCRITORES } & \multicolumn{4}{|c|}{$\begin{array}{c}\text { NÚMERO DE TRABALHOS } \\
\text { ENCONTRADOS }\end{array}$} \\
\cline { 2 - 5 } & 2017 & 2018 & 2019 & Total \\
\hline (Educação de Jovens e Adultos) OR (EJA) & 03 & 03 & 04 & 10 \\
\hline (Formação Docente) OR (Formação Continuada) & 03 & 10 & 04 & 17 \\
\hline (Educação Inclusiva) OR (Inclusão) & 04 & 06 & 02 & 12 \\
\hline
\end{tabular}

Fonte: PPGE-UFPB (2020).

Desses trabalhos, observamos que apenas 07 (sete) focalizavam em distintas perspectivas a inclusão da Pessoa com Deficiência e 05 (cinco) se referiam de modo específico às pessoas surdas, aproximando-se mais da perspectiva da educação bilíngue. Observamos que embora o maior quantitativo de trabalhos fosse na perspectiva da Formação Docente, 17 (dezessete) no total, apenas um trazia a interlocução com a categoria da EJA, sendo este o trabalho de Oliveira (2018), intitulado "O lugar da educação popular na formação continuada de professores da EJA: a construção de novos possíveis no chão da escola pública".

Destacamos, também, que foi possível encontrar a dissertação de Lima (2018), intitulada "A formação continuada de professores do atendimento educacional 
http://dx.doi.org/10.5902/1984686X63606

especializado (AEE) no município de Campina Grande/PB: o antes, o durante e o depois de uma intervenção pedagógica", a qual aborda o tema da formação continuada relacionado à categoria da educação inclusiva, em uma pesquisa de intervenção.

No entanto, nenhum dos trabalhos encontrados nesse interstício apresentou a intersecção entre as categorias EJA, Formação Continuada e Educação Inclusiva.

Tal constatação evidencia o silenciamento das pesquisas no tocante à articulação entre essas três categorias, as quais são, a nosso olhar, imprescindíveis para pensar a inclusão de pessoas jovens e adultas com deficiências na modalidade EJA, bem como pensar a formação de professores para atender pedagogicamente esse perfil de educandos.

Logo, a necessidade de políticas de formação continuada para professores da modalidade em tela, no que tange, também, à inclusão de educandos com deficiência na EJA são imprescindíveis para que a educação seja inclusiva em todas as suas modalidades.

\section{Categorias evidenciadas nas palavras-chave das pesquisas}

Outro aspecto de grande relevância em nossa análise refere-se à construção sequencial das palavras-chave e seus respectivos ordenamentos, a saber:

Educação de Jovens e Adultos. Estudantes com deficiência. Formação docente. Trajetória fenomenológica. (ARAUJO, 2018).

Educação. Formação Inicial. Educação de Jovens e Adultos. (ENVIY, 2019).

Educação Especial. Educação de Jovens e Adultos. Formação Continuada Colaborativa. Prática Pedagógica. (BUENO, 2018).

Educação Especial. Educação de Jovens e Adultos. Deficiência Intelectual. Formação Continuada Reflexiva. (TASSINARI, 2019).

Como podemos ver, são recorrentes, nas 04 (quatro) pesquisas, a Educação de Jovens e Adultos; a Formação Docente aparece em todas, porém, variando em sua especificidade, uma vez que Enviy (2019) restringe-se ao campo da Formação Inicial e Bueno (2018) e Tassinari (2019) ao campo da Formação Continuada, porém, as caracterizando de formas distintas, a primeira constitui-se como colaborativa e, a segunda, reflexiva.

A inserção destas pesquisas no campo da educação inclusiva fica evidenciada nas categorias: Estudantes com Deficiência (ARAUJO, 2018), Educação Especial (BUENO, 
http://dx.doi.org/10.5902/1984686X63606

2018; TASSINARI, 2019), bem como Deficiência intelectual conforme especifica Tassinari (2019).

Cabe salientar que embora Enviy (2019) traga no título de sua dissertação os "contextos inclusivos" (razão pela qual sua pesquisa foi acrescentada a esse escopo analítico), não há nenhuma palavra-chave que faça alusão à Educação Inclusiva, o que evidencia que, em seu texto, a autora apesar de investigar a formação inicial de professores, traz a temática da inclusão apenas enquanto cenário (menção aos contextos inclusivos) e não enquanto objeto de estudo.

Uma vez tendo analisado os títulos e palavras-chaves propostas nas respectivas pesquisas, trazemos na seção a seguir, uma breve contextualização das pesquisas que analisamos.

\section{Breve contextualização das obras analisadas}

Para melhor compreensão dos trabalhos analisados, consideramos importantes sintetizar um pouco de nossas impressões sobre os textos finais, lidos e analisados em sua integralidade.

Em sua dissertação, Enviy (2019) estuda acadêmicos que, uma vez matriculados na disciplina de Estágio em EJA, vivenciam na imersão do estágio junto às escolas, os desafios reais da docência nesta modalidade, de modo a reconhecerem seus nãosaberes para trabalhar nesta modalidade específica. Cabe ressaltar que o estudo se desenvolve no âmbito da formação inicial, de dois componentes curriculares, EJA e Estagio Supervisionado. Embora a questão da inclusão se apresente desde o título da pesquisa, não há um aprofundamento teórico deste campo de estudo, tampouco acerca das questões relacionadas à inclusão das pessoas com deficiência, de modo que o que vemos é a perspectiva de uma inclusão relacionada aos sujeitos da EJA de um modo geral, não aprofundando as especificidades oriundas do processo inclusivo do públicoalvo da Educação Especial.

Araujo (2018) utiliza-se de uma trajetória epistemológica para apresentar a percepção dos docentes da EJA sobre os educandos com deficiência. Toda a análise versa sobre as percepções e os entendimentos dos docentes sobre a EJA, a inclusão e as Pessoas com Deficiências. Por se tratar de um mestrado profissional, cujo produto final deveria incorporar também um projeto de intervenção, a pesquisadora realizou 03 (três) encontros formativos na escola campo de sua pesquisa, atuando sobre os temas 
cujas lacunas formativas foram citadas nas entrevistas. Fica notório o desconhecimento dos docentes sobre os aspectos legais da EJA, bem como sobre a questão de trabalhar com a diversidade na EJA. Há, também, uma discussão sobre o modelo clínico e o social da deficiência.

Bueno (2018), em seu texto dissertativo, realiza por meio de uma pesquisa colaborativa uma formação virtual com professores da EJA, incluindo neste grupo uma professora do Atendimento Educacional Especializado. Assim, a mesma observa as práticas dos docentes e nos encontros formativos online problematiza os contextos vivenciados ou trazidos a partir de sua observação. Interessante ressaltar que uma vez que a autora faz uma opção pelo atendimento educacional especializado construído e ofertado por meio do ensino colaborativo, sua opção revela que na sua concepção o processo inclusivo dos alunos com deficiência é otimizado à medida que se constrói uma rede colaborativa (formada pelo professor da Educação Especial e o professor da sala regular), que reflete em conjunto as demandas relativas aos educandos com deficiências e suas especificidades, tendo como embasamento uma abordagem social da compreensão de ser pessoa com deficiência.

Por sua vez, Tassinari (2019), em sua tese, realiza um estudo sobre a formação e prática do professor da EJA referente ao processo inclusivo de Jovens e Adultos com Deficiência Intelectual. Cabe destacar que a autora ressalta em seu estudo os despreparos dos docentes desta modalidade, bem como a urgente necessidade de superação do mito de que os alunos com deficiência são incapazes de aprender. A mesma também opta por realizar uma caracterização individual das práticas pedagógicas de cada docente participante da pesquisa, analisando de que modo evidenciam a inclusão e/ou exclusão dos alunos com deficiência intelectual, a exemplo de questões como a utilização de materiais adaptados ou sobre a realização de uma adaptação curricular.

Diante do exposto, nos trabalhos analisados acima e mediante a contextualização inicialmente realizada, podemos constatar que as pesquisas realizadas no campo da intersecção da EJA, Formação Docente e Educação Inclusiva ainda são escassas. São necessários novos outros estudos que enfoquem a inclusão da Pessoa com Deficiência nesta modalidade e que problematizem as caraterísticas específicas da EJA, de modo a potencializar contextos formativos cada vez mais imersos nos cotidianos escolares. Por 
http://dx.doi.org/10.5902/1984686X63606

esta razão, aprofundamos, a seguir, o nosso olhar para os aspectos metodológicos apontados nessas pesquisas.

\section{Aspectos metodológicos dos trabalhos analisados}

Sobre os aspectos metodológicos das pesquisas, observamos que todas situam-se no âmbito das pesquisas qualitativas e em contextos formativos, tanto no cenário escolar (ARAUJO, 2018; BUENO, 2018; TASSINARI, 2019), como no espaço universitário, conforme vemos na pesquisa de Enviy (2019). Partindo dessa compreensão, encontramos os seguintes objetivos gerais das pesquisas:

Compreender a percepção dos professores sobre os estudantes com deficiência na modalidade EJA. (ARAUJO, 2018, p. 16).

Analisar aspectos da formação docente inicial, a partir de práticas pedagógicas desenvolvidas na disciplina de Estágio Supervisionado na EJA investigando como no processo de formação inicial as práticas vinculadas às orientações dos acadêmicos na disciplina de Estágio Supervisionado na EJA vem contribuindo para o desenvolvimento do trabalho pedagógico de qualidade desta modalidade. (ENVIY, 2019, p. 16).

Analisar em conjunto com os professores da EJA e o da Educação Especial, suas práticas. (BUENO, 2018, p. 21-22).

Analisar a formação e atuação do professor da Educação de Jovens e Adultos junto aos alunos com deficiência intelectual, matriculados na modalidade de ensino da Educação de Jovens e Adultos. (TASSINARI, 2019, p. 21).

Com exceção de Araujo (2018), as demais autoras apresentam como principais objetivos o verbo analisar, o que implica em investigar um fato ou fenômeno, esquadrinhando seus elementos, a fim de contrapor os aspectos encontrados a uma teoria ou perspectiva teórica. Observemos que ainda no tocante aos objetivos gerais das pesquisas, há uma predominância da percepção e do protagonismo docente sobre os fenômenos educativos estudados.

Sobre a metodologia adotada nas pesquisas, trazemos o Quadro 3, no qual sintetizamos as principais características dos percursos metodológicos das dissertações e tese analisados. 
http://dx.doi.org/10.5902/1984686X63606

Quadro 3 - Caracterização das pesquisas de acordo com os aspectos metodológicos

\begin{tabular}{|c|c|c|c|c|}
\hline & $\begin{array}{l}\text { ARAÚJO } \\
\text { (2018) }\end{array}$ & $\begin{array}{l}\text { ENVIY } \\
\text { (2019) }\end{array}$ & $\begin{array}{l}\text { BUENO } \\
(2018)\end{array}$ & $\begin{array}{l}\text { TASSINARI } \\
\text { (2019) }\end{array}$ \\
\hline Abordagem & Qualitativa & * & $\begin{array}{l}\text { Qualitativa- } \\
\text { Descritiva }\end{array}$ & Qualitativa \\
\hline Procedimentos & $\begin{array}{c}\text { Trajetória } \\
\text { Fenomenológica }\end{array}$ & $\begin{array}{l}\text { Pesquisa } \\
\text { Participante }\end{array}$ & $\begin{array}{l}\text { Pesquisa } \\
\text { Colaborativa }\end{array}$ & Pesquisa-Ação \\
\hline Sujeitos & 11 Professores & $\begin{array}{c}2 \text { professoras e } \\
14 \text { acadêmicas } \\
\text { (graduandas de } \\
\text { pedagogia) }\end{array}$ & $\begin{array}{c}8 \text { Professores da } \\
\text { EJA - Sendo } 01 \\
\text { da Educação } \\
\text { Especial }\end{array}$ & $\begin{array}{l}07 \text { professores do } \\
2 \text { o ciclo do Ensino } \\
\text { Fundamental - EJA }\end{array}$ \\
\hline Lócus & $\begin{array}{c}\text { Centro } \\
\text { de Educação de } \\
\text { Jovens e Adultos }{ }^{3} \\
\text { localizado em } \\
\text { Feira de Santana } \\
\text { - Bahia }\end{array}$ & $\begin{array}{l}\text { Instituição de } \\
\text { Ensino Superior } \\
\text { Privada de } \\
\text { Ponta Grossa }\end{array}$ & $\begin{array}{c}01 \text { escola pública } \\
\text { da Rede Municipal } \\
\text { de Ensino de uma } \\
\text { cidade do interior } \\
\text { do estado de São } \\
\text { Paulo }\end{array}$ & $\begin{array}{l}01 \text { escola pública } \\
\text { municipal, } \\
\text { localizada em um } \\
\text { município da região } \\
\text { norte do Estado de } \\
\text { São Paulo. }\end{array}$ \\
\hline $\begin{array}{l}\text { Técnicas/ } \\
\text { Estratégias }\end{array}$ & $\begin{array}{l}\text { Observação } \\
\text { direta, } \\
\text { questionário e } \\
\text { entrevista }\end{array}$ & $\begin{array}{c}\text { Entrevista } \\
\text { Semiestruturada } \\
\text { - Grupo Focal } \\
\text { (04 encontros) }\end{array}$ & $\begin{array}{c}\text { Roteiros de } \\
\text { observação; } \\
\text { questionários de } \\
\text { caracterização; } \\
\text { roteiros de } \\
\text { entrevista } \\
\text { semiestruturada; } \\
\text { diário de campo; } \\
\text { roteiro inicial para a } \\
\text { formação } \\
\text { colaborativa; roteiro } \\
\text { de questões } \\
\text { norteadoras para a } \\
\text { formação } \\
\text { colaborativa; e, sala } \\
\text { de aula virtual. }\end{array}$ & $\begin{array}{c}\text { Roteiro de } \\
\text { observação em } \\
\text { sala de aula; } \\
\text { roteiro } \\
\text { semiestruturado } \\
\text { de entrevista para } \\
\text { professor da EJA } \\
\text { com alunos com } \\
\text { deficiência } \\
\text { intelectual; diário } \\
\text { de campo; sala } \\
\text { de aula virtual; e, } \\
\text { formação } \\
\text { reflexiva. }\end{array}$ \\
\hline Análise & $\begin{array}{l}\text { Separada por } \\
\text { unidade } \\
\text { significativa }\end{array}$ & $\begin{array}{l}\text { Abordagem } \\
\text { Hermenêutica } \\
\text { Dialética }\end{array}$ & $\begin{array}{l}\text { Análise de } \\
\text { conteúdo com a } \\
\text { categorização } \\
\text { temática }\end{array}$ & $\begin{array}{c}\text { Análise de } \\
\text { Conteúdo de } \\
\text { Categorização } \\
\text { Temática }\end{array}$ \\
\hline
\end{tabular}

Nota: *Dados não explícitos no texto.

Fonte: Elaborado pelos autores a partir dos dados apresentados nos respectivos trabalhos (2020).

Como podemos analisar no quadro acima, há uma predominância pela pesquisa qualitativa em todos os trabalhos apresentados, ainda que no caso de Enviy (2019) tal informação não seja explicitamente colocada em seu trabalho, o que vemos são pesquisas que se constituem a partir de inferências extraídas junto a relações com seres humanos, tal como nos apresenta Silva e Menezes (2001, p. 2) ao tratarem dessa vertente metodológica, afirmando que esta: 
http://dx.doi.org/10.5902/1984686X63606

[...] considera que há uma relação dinâmica entre o mundo real e o sujeito, isto é, um vínculo indissociável entre o mundo objetivo e a subjetividade do sujeito que não pode ser traduzido em números. A interpretação dos fenômenos e a atribuição de significados são básicas no processo de pesquisa qualitativa. Não requer o uso de métodos e técnicas estatísticas. $\mathrm{O}$ ambiente natural é a fonte direta para coleta de dados e o pesquisador é o instrumento-chave.

No tocante aos procedimentos, observamos que há uma predominância de estratégias de pesquisas de caráter interventivo, a exemplo da Pesquisa Participante realizada por Enviy (2019) e das pesquisas de Bueno (2018) e Tassinari (2019), as quais atuam em contextos formativos nas escolas que sediam suas pesquisas, sendo opção de Bueno (2018) a pesquisa colaborativa e de Tassinari (2019) a pesquisa-ação.

Os sujeitos das pesquisas analisadas no Quadro 03 variam em um quantitativo entre 07 e 16 participantes, cabendo ressaltar que em todos os casos, se tratam de professores em exercício ou em formação, como é o caso das graduandas de pedagogia do trabalho de Enviy (2019). Deste modo, com exceção desta autora, as demais situam suas pesquisas em escolas da rede municipal e/ou estadual de suas regiões. Dentre estas, destacamos a pesquisa de Araujo (2018), dada a especificidade de realizar sua pesquisa em uma escola que oferta exclusivamente a EJA, o que confere maior visibilidade para as questões relacionadas a esta modalidade, bem como uma identidade mais fortalecida nesse campo.

Sobre as técnicas e estratégias para a coleta e produção dos dados, destacamos as pesquisas de Bueno (2018) e Tassinari (2019) pela variação das estratégias utilizadas: "(a) roteiros de observação; questionários de caracterização; (b) roteiros de entrevista semiestruturada; (c) diário de campo; roteiro inicial para a formação colaborativa; (d) roteiro de questões norteadoras para a formação colaborativa; (e) sala de aula virtual" (BUENO, 2018, p. 58), o que confere não apenas uma riqueza maior dos dados pesquisados, como também maior profundidade em suas pesquisas.

Por fim, ainda no campo dos aspectos metodológicos, consideramos importante analisar as técnicas de análise adotadas pelas pesquisadoras, observando a escolha de Tassinari (2019) e Bueno (2018) por trabalhar a análise de conteúdo de categorização temática, cujo ponto de partida consiste na mensagem em si, uma vez que: "[...] seja ela verbal (oral ou escrita), gestual, silenciosa, figurativa, documental ou diretamente provocada, necessariamente, ela expressa um significado e um sentido. Sentido que não pode ser considerado um ato isolado" (FRANCO, 2005, p. 13).

Chama-nos a atenção, dentre estes trabalhos, a ausência de uma análise de discurso propriamente dita, de modo que na maior parte são as unidades significativas e as 
http://dx.doi.org/10.5902/1984686X63606

categorias os enfoques trazidos para as análises das pesquisadoras, não aprofundando no tocante aos discursos apresentados pelos participantes em questão.

Feita toda esta caracterização mais ampla das pesquisas analisadas, adentramos mais especificamente nas práticas discursivas das autoras no tocante aos campos discursivos da EJA, da Educação Inclusiva e da Formação Docente, trazendo para tanto alguns recortes de seus textos, a fim de analisá-los de modo mais aprofundado e comparativo aos demais.

\section{Práticas discursivas sobre a EJA, a educação inclusiva e a formação docente}

Presentes em todos os trabalhos analisados, a EJA é sempre apresentada desde seus aspectos históricos de constituição até suas questões mais atuais, dentre as quais destacamos: a EJA e sua incoerente forma de relacionar a afirmação do direito e a negação de sua efetivação, conforme vemos em Enviy (2019, p. 33):

[...] a EJA sempre foi marcada pela incoerência entre a afirmação (existente no plano jurídico, enquanto direito formal dos jovens e adultos à educação básica) e sua negação (na prática, balizada pela falta de políticas públicas concretas à educação, que está longe de ser efetivamente um direito garantido a todos).

No trecho apresentado acima, vemos a constatação da autora de que o que temos vivenciado nos contextos escolares é, na verdade, a negação de um direito, a saber a uma educação pública, gratuita, de qualidade e para todos (BRASIL, 1988), de modo que os cenários percebidos no "chão da escola" se distanciam do que é anunciado em nossos aportes legais, a exemplo da nossa Constituição Federal (BRASIL, 1988) e da nossa Lei de Diretrizes e Bases, Lei 9393/96 (BRASIL,2016).

Esta relação de direito e negação também fica evidenciada no contexto educacional das pessoas com deficiências conforme acrescenta Tassinari (2019, p. 38):

Nota-se que, tanto para as pessoas com deficiência como para os jovens e adultos em defasagem escolar, as discussões sobre o direito à educação, por muito tempo foram ignoradas ou minimizadas, desconsiderando-se o fato de tais grupos exercerem uma demanda real do campo da Educação, reivindicando saberes e fazeres específicos às suas peculiaridades. (TASSINARI, 2019, p. 38).

A autora retoma, portanto, a partir de um cenário histórico, a constatação de que os processos de exclusão dos jovens e adultos com deficiências não se constituem em fatos recentes, mas, sim, processos históricos vividos há muito tempo. Desse modo, observamos 
http://dx.doi.org/10.5902/1984686X63606

que a EJA é descrita em todos os trabalhos analisados como uma modalidade de ensino (BRASIL, 1996; 2000), de modo que Bueno (2018, p. 17) acrescenta que esta:

[...] traz a questão da inclusão em sua base, justamente por ter como público alvo pessoas em diversas idades, provenientes de diferentes regiões, com diferentes vivências e histórias de vida, marcadas, em sua maioria, por momentos de dificuldades, impedimentos de acesso à escola no ensino regular ou, ainda, relatos de fracasso escolar.

Observamos que, para Bueno (2018), a perspectiva de uma educação inclusiva seria aquela que agrega todos os sujeitos excluídos de alguma forma dos seus direitos, sobretudo, do acesso à educação. Nessa perspectiva, Tassinari (2019) caracteriza esta modalidade enquanto espaço da diversidade, pluralidade e singularidade, de modo que ao trazermos o enfoque para os sujeitos alunos que dela fazem parte, encontramos "pessoas com diferenças culturais, étnicas, de gênero, religiosas, com diversas trajetórias e histórias de vida e que, portanto, aspiram por um currículo verdadeiramente flexível e coerente com as suas realidades" (TASSINARI, 2019, p. 63).

A despeito da ausência formativa, vemos na pesquisa de Enviy (2019) uma experiência realizada no contexto da formação inicial das graduandas de pedagogia, para as quais a autora ressalta a potencialidade de uma formação que se correlacione aos contextos escolares, uma vez que "quanto mais o contexto educacional se fizer mais presente no processo formativo de professores, maiores serão as condições desta formação de atender as complexas exigências desta conjuntura" (ENVIY, 2019, p. 41).

Caminho este que precisa ser melhor consolidado, uma vez que a pesquisa de Araújo (2018) nos revela também um desconhecimento, por parte dos professores em exercício, dos marcos legais da modalidade, ao afirmar que:

[...] nas descrições dos sujeitos colaboradores a falta de conhecimento desses documentos que compõem a legislação da Educação de Jovens e Adultos, tem sido grande obstáculo para que desenvolvam uma prática mais efetiva com esses estudantes (ARAUJO, 2018, p. 102).

Mas, para além do desconhecimento de uma base legal que ancore e fundamente a especificidade da modalidade da EJA, observamos também um contexto de sentimento de despreparo no tocante à inclusão, conforme ressalta Araujo (2018, p. 39), cujos "relatos de estranhamento, medo e sentimento de impotência, são ditos, pelos professores entrevistados, como as primeiras sensações ao se descobrirem docentes em um grupo de pessoas tão diferentes". 
http://dx.doi.org/10.5902/1984686X63606

Ainda de acordo com Araujo (2018), os professores colaboradores de sua pesquisa evidenciavam uma lacuna em seus contextos de formação docente inicial e continuada, para lidar com as diversidades presentes em suas salas de aula, principalmente em se tratando de jovens e adultos com deficiências. Esta mesma lacuna formativa é ressaltada por Bueno (2018), todavia a autora destaca, ainda, a demanda suscitada pelos sujeitos em conhecer:

[...] informações técnicas e pedagógicas sobre os diferentes tipos de dificuldade, interação do aluno junto aos professores e demais alunos, e como realizar adaptações, além de ser apontado pelos professores, a importância de se ter o diagnóstico do aluno PAEE e que sejam realizados estudos de caso sobre 0 aluno com quem trabalham, assim como a realização de leituras $\mathrm{e}$ trocas de experiências entre os professores. (BUENO, 2018, p. 117).

Dentre as práticas inclusivas suscitadas nas pesquisas analisadas, ressaltamos 0 modelo de Ensino Colaborativo ou Coensino apresentado por Bueno (2018, p. 41), para a qual:

[...] caracteriza-se pelo trabalho realizado em parceria entre o professor de Educação Especial e o professor da sala regular, no qual as atividades de planejar, avaliar e desenvolver o trabalho em sala são de responsabilidade de ambos, propondo o desenvolvimento da aprendizagem de todos os alunos, sendo PAEE ou não.

Cabe ressaltar que este modelo de ensino ancora-se em uma abordagem social de compreensão da pessoa com deficiência, de modo que a ênfase se concentra nas barreiras atitudinais e físicas do ambiente (e não mais da pessoa) e que, quando minimizadas, auxiliam na melhoria do ensino na sala regular, o que resulta em uma reestruturação escolar, visando torná-la efetivamente inclusiva (BUENO, 2018).

Na perspectiva de reestruturação do ensino, destacamos Tassinari (2019), que em sua pesquisa, chama-nos a atenção para promover uma prática pedagógica do docente para/com o educando com deficiência, que se ancore na compreensão de que os mesmos são capazes de aprender, desde que suas necessidades e potencialidades sejam observadas, ao passo que Bins (2013, p. 41), ao tratar especificamente dos alunos com deficiência intelectual, afirma o seguinte:

A pessoa com deficiência intelectual, como qualquer outro ser humano, está em processo contínuo de desenvolvimento, por isso deve ser valorizada em sua condição de adulta, mesmo que não se enquadre em todas as definições estabelecidas sobre adultez. Suas singularidades devem ser respeitadas, elas devem ser motivadas a construir sua história de vida como sujeitos adultos em desenvolvimento. $O$ ingresso na EJA deve favorecer que comece a ocorrer mudanças biológicas, cognitivas e sociais, a partir dos vivenciais sócios culturais que se estabelecem. 
De modo que para Tassinari (2019, p. 43), se faz necessário compreender "os fatores que contribuem para o aprendizado dos estudantes com deficiência intelectual na EJA; ou seja, estimulá-los a pensar e a refletir, desenvolvendo as suas percepções, sua autonomia, sem, no entanto, infantilizá-los".

A não infantilização dos jovens e adultos com deficiências é um aspecto já mencionado por outros estudos como o de Haas (2015), de modo que observamos que tal prática não apenas desmotiva tais sujeitos de seus processos formativos, como também coloca o professor em um lugar de desconhecimento com relação a seus alunos.

Desse modo, de acordo com Tassinari (2019, p. 91), "para o amadurecimento de uma escola inclusiva e aberta para a diversidade, sobressai a importância da sociedade e da escola em comprometimento com o ensino-aprendizagem do aluno, com ou sem deficiência". Nessa perspectiva, para a autora, o professor constitui-se como uma peçachave de todo o processo, uma vez que sua percepção e suas práticas sobre as potencialidades e necessidades de seu aluno poderão influenciar de modo direto 0 desenvolvimento/aprendizado de seus alunos com deficiências (TASSINARI, 2019).

\section{As inferências sobre os achados nos trabalhos analisados}

Observamos que ao final de sua pesquisa, Araujo (2018) ressalta que após ouvir os sujeitos colaboradores de sua investigação, a formação continuada surge como demanda suscitada pelos próprios participantes como caminho para construção das práticas inclusivas, de modo que "para eles, os estudantes com deficiência, neste caso, os estudantes jovens e adultos, já se encontram nas salas de aula, eles já desenvolvem um trabalho pedagógico, porém, tendo a clareza de que esse fazer pode e deve ser melhor" (ARAUJO, 2018, p. 58). Sendo também achado desta pesquisa a necessidade de:

[...] efetivar uma rede que ofereça o suporte necessário para que seja garantido o acesso ao currículo e que, aos alunos com deficiência seja oferecida uma formação com vistas à autonomia e independência, tanto no espaço escolar como fora dele" (ARAUJO, 2018, p. 104).

Por sua vez, Enviy (2019, p. 109) ressalta o papel do estágio, considerando que "no momento do estágio os acadêmicos têm seu primeiro contato com tal modalidade, surgindo, portanto, suas primeiras dúvidas, inseguranças, medos e receios, o que torna 0 momento lócus fértil para fomentar discussões sobre estas dificuldades". E conclui o seguinte: 
http://dx.doi.org/10.5902/1984686X63606

Enquanto educadores comprometidos com o desenvolvimento de práticas inovadoras, em prol de uma transformação social que vise tornar os espaços escolares cada vez mais inclusivos, é preciso trazer para a discussão quem são os novos sujeitos que estão adentrando aos espaços escolares. Desta forma, se torna urgente que o curso de licenciatura em Pedagogia, que forma educadores, efetive também com eles novas Pedagogias (trans)formadoras, que oportunizem pensar e elaborar novos modelos, com formações em contextos práticos, que permitam recriar uma nova cultura profissional e uma epistemologia de práticas congruentes, superando a lógica dos saberes do senso comum. (ENVIY, 2019, p. 116).

Na pesquisa de Bueno (2018) fica evidenciado o potencial dos horários de trabalho pedagógico coletivo como espaços coletivos de trabalho da equipe educativa, podendo ser esses "espaços produtivos, de engajamento e reflexão docente, partindo das necessidades e vivências dos professores" (BUENO, 2018, p. 118), de modo que a autora reconhece a necessidade de um trabalho coletivo e colaborativo, sendo este articulado e para o qual sejam necessárias as condições de trabalho que possibilitem tais demandas.

Por fim, ao observarmos os achados explicitados na pesquisa de Tassinari (2019), constatamos que a mesma ressalta que o desconhecimento/despreparo dos docentes para o desenvolvimento de uma prática inclusiva constitui-se em um aspecto preocupante, pois, segundo assevera essa mesma pesquisadora, se "[...] pretendemos construir uma escola diversa e inclusiva, urge o rompimento tanto com o amadorismo como com uma formatação homogeneizadora de uma prática pedagógica excludente" (TASSINARI, 2019, p. 99-100).

Nessa direção, os resultados de sua pesquisa apresentam duas importantes premissas:

Os resultados deixaram transparente que, de um lado, os professores participantes, de forma geral, se mostram favoráveis à inclusão de alunos com deficiência intelectual na EJA, e, por outro, apontaram fatores que dificultam sua atuação com esses alunos, tais como: falta de formação para trabalhar com eles, necessidade do apoio de profissionais especializados para acompanhar o aluno e orientá-los em sua prática pedagógica. (TASSINARI, 2019, p. 111, grifo nosso).

Os professores foram unânimes em reconhecer que não se sentem preparados para a inclusão escolar do aluno com deficiência intelectual dada a ausência de um preparo mais teórico-técnico-metodológico, bem como do apoio de profissionais especializados para acompanhar o aluno e orientá-los em sua prática pedagógica. (TASSINARI, 2019, p. 115, grifo nosso).

A falta de formação e a necessidade de apoio constituem-se em entraves para a efetivação de uma educação inclusiva, o que corrobora aos achados de Brito (2017). Sendo o despreparo docente ressaltado não apenas na pesquisa de Tassinari (2019), como também das demais aqui analisadas: Araujo (2018), Bueno (2018) e Enviy (2019). 
http://dx.doi.org/10.5902/1984686X63606

De um modo geral, os achados finais destes trabalhos corroboram entre si, nos permitindo compreender a educação inclusiva enquanto paradigma ainda não alcançado em sua totalidade, além de evidenciar que na modalidade da EJA especificamente para avançar na direção da efetiva inclusão, se faz necessário investir esforços na formação docente e nas práticas colaborativas, sendo estas duas importantes parceiras nessa empreitada.

\section{Considerações finais}

Ao final da realização desse Estado do Conhecimento, observamos que, embora estudadas de formas isoladas, a Educação de Jovens e Adultos, a Formação Docente e a Educação Inclusiva constituem-se em áreas fecundas de novas investigações e que, quando interseccionalizadas, evidenciam um terreno pouco explorado.

Mediante este cenário, destacamos enquanto principais resultados da presente pesquisa: 1- A necessidade do fortalecimento de um trabalho mais colaborativo em que professores da sala regular e professores do atendimento educacional especializado dialoguem sobre o processo inclusivo de seus educandos com deficiência, conforme evidenciado nas pesquisas de Tassinari (2019) e Bueno (2019). 2- A urgência de investir em formação continuada que uma vez estando relacionada a prática e as realidades encontradas nos contextos escolares se consolidem como espaço de reflexão e promoção de novas práticas, tais como a pesquisa de Bueno (2019) e Araujo (2018). 3- O urgente suporte de um apoio especializado aos docentes por meio da contratação de profissionais que possam somar nesses processos inclusivos. 4- A demanda de fortalecer uma identidade docente para atuar na EJA, que se construa desde a formação inicial, por meio de vivências e estágios que permitam, ao professor em formação, experenciar a realidade e os desafios de uma EJA inclusiva, tal como ressalta Enviy (2019).

Em síntese, nas pesquisas de Bueno (2019), Tassinari (2019), Enviy (2019) e Araujo (2018), ficam evidenciados os discursos docentes de despreparo frente aos processos inclusivos de jovens e adultos com deficiências, bem como a necessidade de pesquisas que, uma vez construídas junto aos seus sujeitos participantes, fortaleçam e potencializem contextos colaborativos nos espaços formativos, como estratégias resolutivas frente aos desafios inerentes à construção das Escolas Inclusivas.

A exemplo das pesquisas de Siems (2012), Haas (2015) e Silva e Campos (2018), aproveitamos do exercício por ora realizado para atualizar os achados dos autores, bem 
como reafirmar a necessidade de novos estudos que inter-relacionem as áreas aqui exploradas.

Dito isto, concluímos o presente estado do conhecimento ressaltando que na intersecção das modalidades da Educação de Jovens e Adultos e da Educação Especial, a formação docente se constitui em um objeto de estudo pouco investigado, ainda que esta se apresente em todas as pesquisas analisadas como sendo um dos principais instrumentos para a construção de uma educação de fato inclusiva e pertinente aos jovens e adultos com deficiências que dela necessitam.

Por fim, observamos que em todas as investigações realizadas tanto no contexto da formação inicial, quanto da formação continuada, é ressaltada a urgente necessidade de trazer as realidades escolares e os desafios inclusivos de modo mais profundo aos contextos formativos dos docentes e que só por meio de investimentos nessa área, poderemos, enfim, potencializar uma Educação de Jovens e Adultos verdadeiramente inclusiva.

\section{Referências}

ARAUJO, Maria A. F. P. de. Percepções docentes sobre a inclusão de estudantes com deficiência na Educação de Jovens e Adultos: (Im) possibilidades no âmbito da formação continuada. 2018. 129 f. Dissertação (Mestrado em Educação) - Programa de Pós-Graduação em Educação de Jovens e Adultos - MPEJA, Universidade do Estado da Bahia, 2018.

BANCO DIGITAL DE TESES E DISSERTAÇÕES. Site Institucional. 2020. Disponível em: https://bdtd.ibict.br/vufind/. Acesso em: 25 set. 2020.

BARDIN, Laurence. Análise de conteúdo. Trad.: Luis Antero Reto. São Paulo: Edições 70, 2011.

BINS, Katiuscha Lara Genro. Adultos com deficiência intelectual incluídos na educação de jovens e adultos: apontamentos necessários sobre adultez, inclusão e aprendizagem. 2013. 108 f. Tese (Doutorado em Educação) - Faculdade de Educação, Pontifícia Universidade Católica de Rio Grande do Sul, Porto Alegre, 2013.

BRASIL. Constituição da República Federativa do Brasil. Brasília: Senado Federal, Centro Gráfico, 1988, p. 137 -141.

BRASIL. Lei Darcy Ribeiro (1996). LDB : Lei de diretrizes e bases da educação nacional:

Lei no 9.394, de 20 de dezembro de 1996. Estabelece as diretrizes e bases da educação nacional. 13. ed. Brasília: Câmara dos Deputados, Edições Câmara, 2016. Disponível em: bd.camara.leg.br Acesso em: 15 mar. 2021 
BRASIL. Conselho Nacional de Educação (CNE). Câmara de Educação Básica. Parecer n. - 11, de $\mathbf{1 0}$ de maio de 2000. Estabelece as Diretrizes Curriculares Nacionais para a Educação de Jovens e Adultos. Diário Oficial da União, Brasília, 9 jun. 2000.

BRASIL. Lei no 13.146, de 6 de julho de 2015. Institui a Lei Brasileira de Inclusão da Pessoa com Deficiência (Estatuto da Pessoa com Deficiência). Disponível em: http://www.planalto.gov.br/ccivil_03/_ato2015-2018/2015/lei//13146.htm. Acesso em: 15 fev. 2020.

BRITO, Carla Eugênia Nunes. Inclusão em contextos, contrastes e desafios: um estudo de caso sobre a aprendizagem na educação básica em Aracaju/Sergipe. 2018. 151 f. Dissertação (Mestrado em Educação) - Universidade Tiradentes, Aracaju, UNIT, 2018.

BUENO, Melina Brandt. Educação de Jovens e Adultos: formação continuada colaborativa entre professores da sala comum e da educação especial. 2018. 143 f. Dissertação (Mestrado) - Universidade Federal de São Carlos, São Carlos, 2018.

CATÁLOGO DE TESES E DISSERTAÇÕES CAPES. Site Institucional. 2020. Disponível em: https://catalogodeteses.capes.gov.br/catalogo-teses/\#!/. Acesso em: 25 set. 2020.

CARVALHO, Rosita Edler. Educação Inclusiva: com os pingos nos "is". 10 ed. Porto Alegre: Mediação, 2014.

ENVIY, Perla Cristiane. Reflexões no processo ensino/aprendizagem e suas implicações na formação inicial docente: contextos inclusivos na Educação de Jovens e Adultos. 2019. 130 p. Dissertação (Mestrado em Educação) - Universidade Estadual do Centro-Oeste, Irati, 2019.

FRANCO, Maria Laura Puglisi Barbosa. Análise de conteúdo. 2. ed. Brasília: Liber Livros, 2005.

HAAS, Clarissa. Educação de jovens e adultos e educação especial: a (re) invenção da articulação necessária entre as áreas. Educação, Santa Maria, v. 40, n. 2, p. 347-360, maio/ago. 2015. Disponível em:

https://periodicos.ufsm.br/reveducacao/article/view/9038/pdf. Acesso em: 10 nov. 2019.

\section{LIMA, Maria das Graças de et al. A formação continuada de professores do} atendimento educacional especializado (AEE) em Campina Grande/PB: 0 antes, o durante e o depois de uma intervenção pedagógica. 2018. 134 f. Dissertação (Mestrado em Educação) - Programa de Pós-Graduação em Educação, Universidade Federal da Paraíba, João Pessoa, 2018.

MACHADO, Maria Margarida. A educação de jovens e adultos no Brasil pós-Lei no 9.394/96: a possibilidade de constituir-se como política pública. Em aberto, v. 22, n. 82, 2009.

MOROSINI, Marília Costa; FERNANDES, Cleoni Maria Barboza. Estado do conhecimento: conceitos, finalidades e interlocuções. Educação Por Escrito, Porto Alegre, v. 5, n. 2, p. 154-164, 2014. 
http://dx.doi.org/10.5902/1984686X63606

OLIVEIRA, Adriana Bastos. O lugar da Educação Popular na formação continuada de professores da EJA: a construção de novos possíveis no chão da escola pública. 2018. 225 f. Dissertação (Mestrado em Educação) - Universidade Federal da Paraíba, João Pessoa, 2018.

PORTAL DE PERIÓDICOS CAPES/MEC. Site Institucional. 2020. Disponível em: https://www.periodicos.capes.gov.br/. Acesso em: 30 jan. 2020.

\section{PPGE-UFPB. Repositório do Programa de Pós-Graduação em Educação da} Universidade Federal da Paraíba. 2020. Disponível em: https://repositorio.ufpb.br/. Acesso em 25 jan. 2020.

SIEMS, Maria Edith Romano. Educação de jovens e adultos com deficiência: saberes e caminhos em construção. Educação em foco, Juiz de Fora, v. 16, n. 2, p. 61-79, 2012.

SILVA, Maria do Carmo Lobato da; CAMPOS, Juliane Aparecida de Paula Perez. Formação de professores para inclusão escolar na modalidade de Educação de Jovens e Adultos: análise de pesquisas. Revista on line de Política e Gestão Educacional, Araraquara, v. 22, n. 3, p. 1154-1167, 2018.

SILVA, Edna Lúcia da; MENEZES, Estera Muszkat. Metodologia da Pesquisa e Elaboração de Dissertação. 3. ed. ver. e atual. Universidade Federal de Santa Catarina. Programa de Pós-Graduação em Engenharia de Produção. Laboratório de Ensino a Distância. 2001. Disponível em:

http://cursos.unisanta.br/civil/arquivos/Pesquisa_Cientifica_metodologias.pdf Acesso em: ago. 2015.

TASSINARI, Ana Maria. Formação e prática pedagógica de professores da EJA junto a estudantes com deficiência intelectual. 2019. 157 f. Tese (Doutorado em Educação Especial) - Programa de Pós-Graduação em Educação Especial, Universidade Federal de São Carlos, São Carlos, 2019.

\section{Notas}

\footnotetext{
${ }^{1}$ Neste trabalho, as autoras realizam um recorte temporal de 2008 a 2016, fato este que nos impulsionou a optar pelo ano de 2017 como ponto de partida do presente levantamento.

2 De acordo com o Portal Gazeta do Povo (2019), dos 11,3 milhões de analfabetos que o Brasil apresentava em 2018 (segundo dados da PNAD), a Paraíba encontrava-se em 4ํlugar no ranking das maiores taxas por estado, tendo um total de $16,1 \%$ de sua população ainda não alfabetizada.

${ }^{3}$ Colégio Estadual, conhecido como Centro de Educação de Jovens e Adultos por ofertar apenas esta modalidade em seus três turnos (ARAUJO, 2018).
}

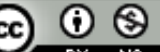

This work is licensed under a Creative Commons Attribution-NonCommercial 4.0 International (CC BY-NC 4.0) 